\title{
Coös County Youth and Out-of-School Activities Patterns of Involvement and Barriers to Participation
}

ERIN HILEY SHARP

$\mathrm{R}$ esearch across diverse settings has provided strong evidence that participation in structured activities benefits adolescents. Greater participation in structured activities like student government, sports teams, and service clubs has been linked to better grades, higher expectations for the future, greater school attachment, and lower rates of substance use and delinquency across the high school years. Results from the Coös Youth Study show that these findings hold in this rural context. ${ }^{1}$ Findings have also emerged from our study in terms of differences between male and female students' participation in structured out-of-school activities. In this fact sheet, we draw from surveys administered to a cohort of 416 participants in 7th grade in 2008, again when they were in 8th grade in 2009, and most recently as 10th graders in 2011 to look at patterns of participation in structured activities over time and whether male and female students differ in these patterns of participation. Second, we draw from questions added to the 2011 survey of 10th graders to examine Coös County youths' perceptions about what kinds of barriers have kept them from getting more involved in structured out-of-school activities.

\section{Differences in Levels of Participation in Structured Out-of-School Activities Over Time for Males and Females}

Longitudinal analysis techniques ${ }^{2}$ were used to identify patterns of participation in structured out-of-school activities across 7 th, 8 th, and 10th grades. Three distinct participation patterns were identified: consistently low involvement (24 percent), consistently average involvement (45 percent), and consistently high involvement (26 percent) in structured activities. Students' level of involvement in structured activities was fairly stable across 7 th, 8 th, and 10th grades, meaning that if a student reported low involvement in 7 th grade, she also typically reported low involvement in 8 th and

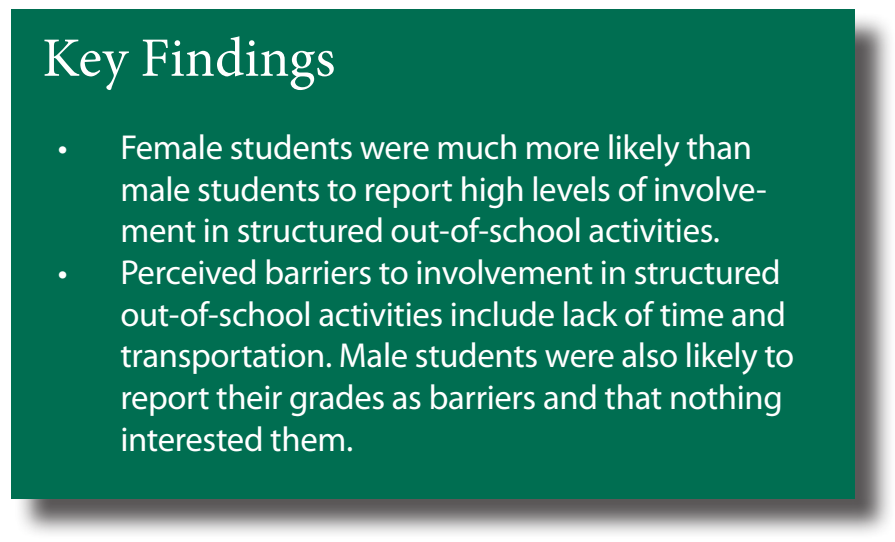

10th grades. Male and female students differed significantly in their levels of involvement (see Figure 1). Female students were much more likely than male students to report high levels of involvement in structured out-of-school activities.

\section{Youths' Perceptions About Barriers to Their Involvement in Structured Activities}

We know that out-of-school activities are important to youth and a starting place for understanding how involvement can be increased is to explore adolescents' perceptions of barriers to their own participation. When they were in 10th grade, we asked participants what kinds of things kept them from getting involved in more structured activities during the current year. Overall, 37 percent of students reported that they thought there were barriers limiting their participation. Interestingly, those youth who were least involved were also the least likely to report barriers (27 percent). This low percentage was a bit surprising, but it may be that students do not recognize that there are specific barriers influencing their choices.

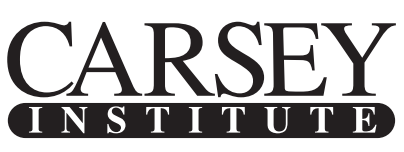

BUILDiNg KNOWLEDGE FOR FAmilies And Communities
Huddleston Hall, 73 Main Street, Durham, NH 03824

(603) 862-2821 • www.carseyinstitute.unh.edu

This work was supported by the Neil and Louise Tillotson Fund of the New Hampshire Charitable Foundation. 
Figure 1: Percentage of Students identified in the THREE DISTINCT PROFILES OF LEVEL OF INVOLVEMENT IN STRUCTURED OUT-OF-SCHOOL ACTIVITIES OVER TIME (PATTERNS FROM 7TH, 8TH, AND 1OTH GRADES)
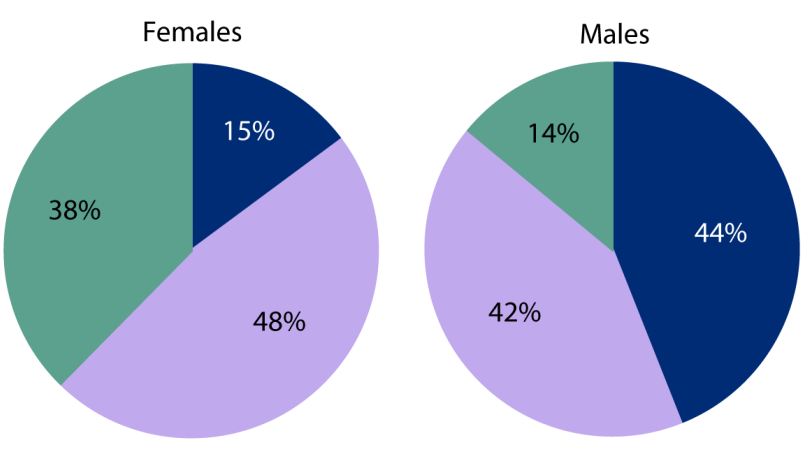

- Consistently
low involvement

$$
\begin{gathered}
\text { Consistently } \\
\text { average } \\
\text { involvement }
\end{gathered}
$$

$$
\begin{gathered}
\text { Consistently } \\
\text { high } \\
\text { involvement }
\end{gathered}
$$

Results for those students who did report barriers showed that the two most commonly reported barriers to participation in structured activities were "don't have time" and "transportation" (see Figure 2). The perception of youths who reported that they "don't have time" for participation in structured activities is interesting given that the Coös County students who were most involved in structured activities were also those who were most likely to have a part-time job and to report spending time in unstructured forms of leisure like hanging out with friends. It is not surprising that youths living in a rural context believed that transportation is a barrier to involvement. Focusing on male students, we found that they were significantly more likely to report that "nothing interested me" and "grades" were barriers to their involvement.

\section{Strategies to Increase Participation in Structured Out-of-School Activities}

Our findings highlight the need to pay particular attention to Coös County males' involvement in structured out-of-school activities and point to some specific strategies that may increase participation. Schools and community leaders could reach out to families and explore ways to improve transportation options for after-school programming and also work with families to communicate the benefits of choosing to spend free time in structured out-of-school activities. There are also school-based programs like TimeWise: Taking Charge of Leisure Time ${ }^{3}$ designed specifically to help adolescents find ways to use their free time in more positive and meaningful ways. In response to our findings for male students, schools could consider additional academic supports and examine policies related to grade point average requirements for participation in extracurricular
Figure 2: Percentage of 10th grade students Who PERCEIVE SPECIFIC BARRIERS TO INVOLVEMENT IN STRUCTURED OUT-OF-SCHOOL ACTIVITIES

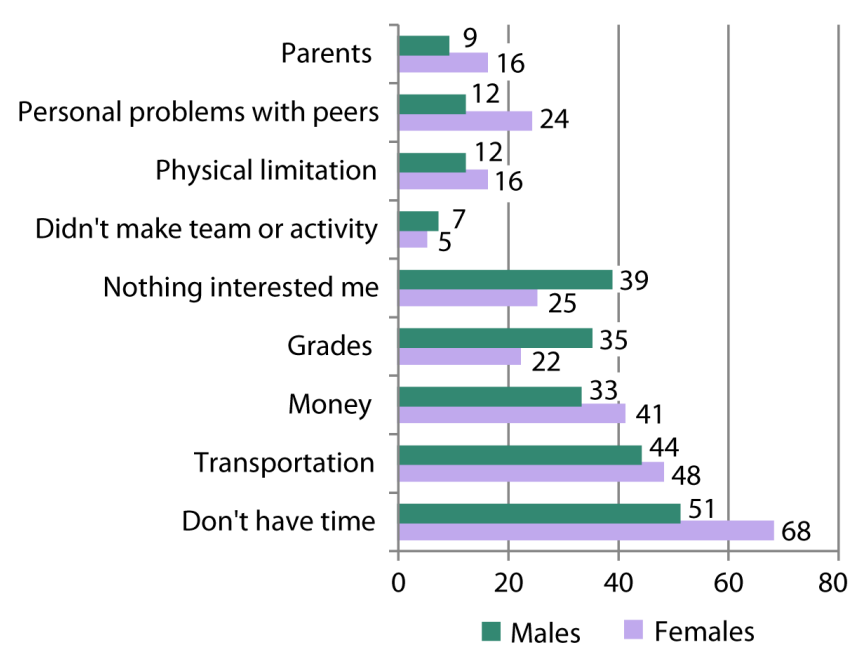

activities. Finally, schools and communities could work together to explore ideas for increasing the range of activities available, especially in order to offer activities that would be of interest to Coös County boys.

\section{E N D N O T ES}

1. Erin Hiley Sharp, "Out of School Time Matters: Activity Involvement and Positive Development Among Coös County Youth," Issue Brief No. 17 (Durham, NH: Carsey Institute, University of New Hampshire, 2010); Erin Hiley Sharp, "Too Much Free Time: Coös County Youth Who Are Least Involved in Out-of-School Activities Are Most Likely to Use Drugs and Alcohol," Issue Brief No. 18 (Durham, NH: Carsey Institute, University of New Hampshire, 2010).

2. Latent Transition Analysis across the three waves of data was performed using MPLUS. Variables were standardized and the best-fitting latent structure was determined using examination of multiple solutions, starting with one latent profile and increasing hierarchically. The three-profile salutation has the best relative fit based on the AIC, BIC, and sample adjusted BIC.

3. Linda L. Caldwell, TimeWise: Taking charge of free time curricular for middle school students (Scotts Valley, CA: ETR Associates, 2004).

\section{A B OUT THE AUTHOR}

Erin Hiley Sharp, $\mathrm{PhD}$, is a Carsey Institute faculty fellow and an assistant professor in family studies at the University of New Hampshire (erin.sharp@unh.edu).

\section{A C K N O W LED G M E N T S}

The Rural Youth Study Team thanks the students participating in this research project and the superintendents, principals, guidance counselors, teachers, and administrators who helped the team collect these data. Thank you to Amy Sterndale and Laurel Lloyd for their editorial assistance. Also, special thanks to fellow members of the Rural Youth Research Team, including Eleanor Jaffee, Cesar Rebellon, Corinna Jenkins Tucker, and Karen Van Gundy. 